\title{
Preparation of Graphene Oxide Composites and Assessment of Their Adsorption Properties for Lanthanum (III)
}

\author{
Jie Zhou ${ }^{1,2}$, Xiaosan Song ${ }^{1,2, *}$, Boyang Shui ${ }^{1,2}$ and Sanfan Wang ${ }^{1,2}$ \\ 1 School of Environment and Municipal Engineering, Lanzhou Jiaotong University, No. 88, Anning West Road, \\ Lanzhou 730070, China; 0619100@stu.lzjtu.edu.cn (J.Z.); 201701131@stu.lzjtu.edu.cn (B.S.); \\ wsf1612@mail.lzjtu.cn (S.W.) \\ 2 Engineering Research Center of Comprehensive Utilization of Water Resources in Cold and Drought Areas, \\ Ministry of Education, No. 88, Anning West Road, Lanzhou 730070, China \\ * Correspondence: songxs@mail.lzjtu.cn
}

check for updates

Citation: Zhou, J.; Song, X.; Shui, B.; Wang, S. Preparation of Graphene Oxide Composites and Assessment of Their Adsorption Properties for Lanthanum (III). Coatings 2021, 11, 1040. https://doi.org/10.3390/ coatings11091040

Academic Editor: Philippe Evon

Received: 8 August 2021

Accepted: 24 August 2021

Published: 29 August 2021

Publisher's Note: MDPI stays neutral with regard to jurisdictional claims in published maps and institutional affiliations.

Copyright: (c) 2021 by the authors. Licensee MDPI, Basel, Switzerland. This article is an open access article distributed under the terms and conditions of the Creative Commons Attribution (CC BY) license (https:// creativecommons.org/licenses/by/ $4.0 /)$.
Abstract: In this study, graphene oxide (GO) was prepared using the improved Hummers' method, and GO was carboxylated and modified into hydroxylated graphene oxide $(\mathrm{GOH})$. Diatomaceous earth (DE), which exhibits stable chemical properties, a large specific surface area, and high porosity, as well as chitosan/magnetic chitosan, was loaded by solution blending. Subsequently, carboxylated graphene oxide/diatomite/chitosan (GOH/DCS) and carboxylated graphene oxide/diatomite/magnetic chitosan (GOH/DMCS) composites were prepared through simple solid-liquid separation. The results showed that the modified GOH/DCS and GOH/DMCS composites could be used to remove lanthanum $\mathrm{La}(\mathrm{III})$ ), which is a rare earth element. Different factors, such as initial solution concentration, $\mathrm{pH}$ of the solution, adsorbent dosage, adsorption contact time, and adsorption reaction temperature, on adsorption, were studied, and the adsorption mechanism was explored. An adsorption-desorption recycling experiment was also used to evaluate the recycling performance of the composite material. The results show that at the initial solution concentration of $50 \mathrm{mg} \cdot \mathrm{g}^{-1}, \mathrm{pH}=8.0,3 \mathrm{~g} \cdot \mathrm{L}^{-1}$ adsorbent dosage, reaction temperature of $45^{\circ} \mathrm{C}$, and adsorption time of $50 \mathrm{~min}$, the adsorption effect is the best. The adsorption process is more in line with the pseudo-second-order kinetic model and Langmuir model, and the internal diffusion is not the only controlling effect. The adsorption process is an endothermic and spontaneous chemical adsorption process. The maximum adsorption capacity of $\mathrm{GOH} / \mathrm{DMCS}$ for $\mathrm{La}(\mathrm{III})$ at $308 \mathrm{~K}$ is $302.51 \mathrm{mg} / \mathrm{g}$ through model simulation. After four adsorptiondesorption cycles, the adsorption capacity of the GOH/DMCS composite for La(III) initially exceeded $74 \%$. So, GOH/DMCS can be used as a reusable and efficient adsorbent.

Keywords: graphene oxide; composite materials; lanthanum; adsorption

\section{Introduction}

Lanthanum (La) is a metal used in optical glasses, alloys, catalysts, and ceramics [1]. To extract trace elements of this rare earth metal, significant quantities of water and chemical reagents are needed, through a variety of chemical procedures. As a result, chemical reagents, rare earth elements, and radioactive substances end up in wastewater, which destroys surrounding vegetation, causing serious environmental pollution and affecting the lives of nearby residents [2].

Treating wastewater that contains rare earth elements is a complex and universal ecological problem. Membrane separation, photocatalysis, electrolysis, ion exchange, and adsorption are commonly used for wastewater treatment. The adsorption method is widely used because of its many advantages, such as low cost, a wide range of applications, ease of operation, and effectiveness in removing pollutants from the water [3]. For instance, Iannicelli-Zubiani et al. [4] developed an effective adsorbent for aqueous rare earths recovery, in which activated carbon (AC) was modified with pentaethylenehexamine. The strong improvement in the efficiency values detected by using modified carbons (uptake 
$100 \%$ until initial concentrations of about $2600 \mathrm{ppm}$ and release over 95\%) demonstrated that the coordination mechanism due to the modifying agent is effective. Abdel-Magied et al. [5] studied the adsorption properties of rare earth lanthanum by hierarchical porous zeolitic imidazolate frameworks nanoparticles (ZIF-8 NPs) prepared by a template-free method at room temperature using water. Adsorption equilibrium was reached after $7 \mathrm{~h}$ and moderate adsorption capacity was obtained for lanthanum $\left(28.8 \mathrm{mg} \cdot \mathrm{g}^{-1}\right)$ at a $\mathrm{pH}$ of 7.0 . Kusrini et al. [6] investigated a biosorbent derived from the inner part of durian (Durio zibethinus) rinds. La ion was efficiently adsorbed by the biosorbent with optimum adsorption capacity as high as $71 \mathrm{mg}$ La per gram biosorbent. The removal of lanthanum is due to the favorable chelation and strong chemical interactions between the functional groups on the surface of the biosorbent and the metal ions. If the REE concentration in wastewater is high, biological adsorption, extraction, and traditional zeolite, clay, and activated carbon adsorption can be used. Among the above methods, adsorption has been widely concerned and applied because of its simple operation, low cost, and high efficiency. Nanomaterials (NMs) provide a promising technology for wastewater with very low REE concentration because of its potential high adsorption efficiency as an adsorbent. Thus, research on the preparation and modification of efficient and reusable nanomaterials adsorbents is an essential part of realizing sustainable industrial development, protecting the environment and reducing pollution.

Nanomaterial adsorbents have many excellent physical and chemical properties, but there are limits to their applications [7]. Graphene oxide (GO), a graphene derivative, easily aggregates or accumulates between layers, with a decreased adsorption specific surface area that can weaken its adsorption effects [8,9]. Thus, modified GO materials have become a hot research topic. Nanocomposites are sometimes known as free radical substitutes in traditionally filled or blended polymers [10]. However, graphene oxide sheets can only be dispersed in aqueous media that are incompatible with most organic polymers due to their hydrophilic properties.

Presently, there are only two methods to modify the hydrophilicity of graphene oxide: magnetic modification [10] and chemical functionalization. In chemical functionalization, the exfoliation behavior of graphite oxide can be changed by modifying its surface properties, and functional groups such as amide and carbamate bonds will form on the carboxyl and hydroxyl groups of graphite oxide, respectively. As a result, this reduces the hydrophilicity of graphene oxide sheets [11].

Nanomaterials have a paradoxical combination of excellent performance with restricting limitations [12]. This makes them a vital topic for developing and preparing high-efficiency and recyclable green adsorbents to improve the adsorption and removal of water pollutants by the modification of graphene oxide-based materials. Specifically, one area of concern is that graphene oxide-based composite materials are difficult to separate from water [13]. Therefore, this study provides a reference for the removal of heavy metals from wastewater, to alleviate water pollution and facilitate ecological construction.

In this work, magnetic modified chitosan (CS) was compounded with hydroxylated graphene oxide $(\mathrm{GOH})$ and diatomaceous earth $(\mathrm{DE})$. This study focused on enhancing the adsorption capacity and effectively reducing the hydrophilicity of graphene oxide sheets, as well as creating graphene oxide-based composite materials that are easily separated in water to realize material recycling. We assessed the adsorption behavior of La(III) by diatomite and magnetic chitosan-modified graphene oxide-based adsorbents. In addition, scanning electron microscopy (SEM), Fourier transform infrared spectroscopy (FTIR), X-ray diffraction (XRD), zeta potential analysis (Zeta potential), and a vibrating sample magnetometer (PPMS-VSM) were used to characterize the materials, surface morphology, chemical structures, compositions, and their physical and magnetic properties. The modified composite materials (GOH/DCS and GOH/DMCS) were used for static adsorption experiments on the target pollutant, $\mathrm{La}(\mathrm{III})$, and the effects of five factors on the adsorption effect were investigated. Specifically, the initial concentration of the solution, $\mathrm{pH}$ value of the solution, adsorbent dosage, adsorption contact time, and the adsorption 
reaction temperature were assessed. The adsorption process was fitted and analyzed by adsorption kinetics, isotherms, and thermodynamics. Then, regeneration experiments to assess the adsorption saturated GOH/DMCS were carried out to evaluate the regeneration performance of the composites.

\section{Materials and Methods}

\subsection{Chemicals and Reagents}

All chemical reagents used for testing were analytically pure or of a higher grade, including graphite powder, $\mathrm{H}_{2} \mathrm{SO}_{4}, \mathrm{H}_{3} \mathrm{PO}_{4}, \mathrm{KMnO}_{4}, \mathrm{H}_{2} \mathrm{O}_{2}, \mathrm{HCl}$, absolute ethanol, $\mathrm{NaOH}$, $\mathrm{C}_{2} \mathrm{H}_{3} \mathrm{ClO}_{2}$, diatomite, chitosan ( $\mathrm{CS}$, deacetylation degree $>90 \%$ ), $\mathrm{CH}_{3} \mathrm{COOH}$, nano $\mathrm{Fe}_{3} \mathrm{O}_{4}$, and $\mathrm{C}_{5} \mathrm{H}_{8} \mathrm{O}_{2}$. All aqueous solutions were prepared with deionized water.

\subsection{Preparation of Materials}

Graphene oxide was prepared using the improved Hummers' method [14]. The prepared graphite oxide was ultrasonically treated in deionized water for 30 min to fully disperse and exfoliate the graphite oxide, and the GO hydrosol concentration was $2 \mathrm{~g} / \mathrm{L}$. Then, $2.0 \mathrm{~g}$ of sodium hydroxide was added and stirred until completely dissolved, which was followed by the addition of $3.0 \mathrm{~g}$ of chloroacetic acid, which was ultrasonically dispersing for $1 \mathrm{~h}$. Then, the solution was magnetically stirred for $24 \mathrm{~h}$ under constant heating at a temperature of $25^{\circ} \mathrm{C}$, and the mixed solution was centrifuged and washed with anhydrous ethanol three times. Afterward, the mixture was washed with ample amounts of deionized water several times until the $\mathrm{pH}$ was close to 6.0. Then, the mixed solution was dried in an oven at $60^{\circ} \mathrm{C}$ and grounded and sieved with a 200-mesh sieve to obtain the carboxylated graphite oxide. Finally, the carboxylated graphite oxide was uniformly dispersed in quantitative distilled water by ultrasonic stripping to prepare the carboxylated graphene oxide hydrosol $(\mathrm{GOH})$ at a concentration of $2 \mathrm{~g} / \mathrm{L}$.

To prepare the magnetic chitosan, $0.3 \mathrm{~g}$ of chitosan was dissolved in $50 \mathrm{~mL}$ of $2 \%$ glacial acetic acid solution and heated and stirred until completely dissolved. Then, $0.15 \mathrm{~g}$ of nano $\mathrm{Fe}_{3} \mathrm{O}_{4}$ was added to the above solution and mechanically stirred until it was thoroughly dispersed in the chitosan solution. Then, $2.0 \mathrm{~mL}$ of glutaraldehyde was added to the mixed solution and mechanically stirred at $60{ }^{\circ} \mathrm{C}$ for $4 \mathrm{~h}$. The obtained product was washed with ethanol and deionized water several times until it reached a $\mathrm{pH}$ of 6 , and then, it was dried in a vacuum drying oven at $60{ }^{\circ} \mathrm{C}$ for $12 \mathrm{~h}$. Finally, magnetic chitosan (MCS) was prepared by grinding and sieving with a $200-$ mesh sieve.

The prepared carboxylated graphite oxide was ultrasonically treated in deionized water for $30 \mathrm{~min}$, and the GOH hydrosol concentration was $2 \mathrm{~g} / \mathrm{L}$. First, $1.0 \mathrm{~g}$ of chitosan was weighed and added to $50 \mathrm{~mL}$ of $3 \%$ glacial acetic acid solution, heated, and stirred until it was fully dissolved. Then, $3 \mathrm{~g}$ of diatomite was added into the GO-COOH suspension, which was returned to room temperature. Then, it was ultrasonicated for $1 \mathrm{~h}$, magnetically stirred for $12 \mathrm{~h}$, and vacuum filtrated after washing with water. Then, the material was dried to achieve a constant weight in a drying oven at $60{ }^{\circ} \mathrm{C}$, after which it was removed, ground, and placed through a 200-mesh sieve to prepare the carboxylated graphene oxide/diatomite/chitosan (GOH/DCS) material.

The prepared carboxylated graphite oxide was ultrasonically treated in deionized water for $30 \mathrm{~min}$. The concentration of the GO hydrosol was $2 \mathrm{~g} / \mathrm{L}$. First, $1.0 \mathrm{~g}$ of magnetic chitosan and $3 \mathrm{~g}$ of diatomite were weighed and added to the suspension of GO-COOH in turn, ultrasonicated for $1 \mathrm{~h}$, and magnetically stirred for $12 \mathrm{~h}$. The obtained product was washed with ethanol and deionized water several times until the $\mathrm{pH}$ was 6 and then dried in a vacuum drying oven at $60{ }^{\circ} \mathrm{C}$ for $12 \mathrm{~h}$. Finally, the product was grounded and screened with a 200-mesh sieve to prepare the carboxylated graphene oxide/diatomite/magnetic chitosan (GOH/DMCS) composite material. 


\subsection{Testing and Characterization}

The materials were characterized by scanning electron microscope (SEM), Fourier transform infrared spectroscopy (FT-IR), X-ray diffraction (XRD), zeta potential analysis, and vibrating sample magnetometer (PPMS-VSM). The basic information of the instruments is shown in Table 1.

Table 1. Main characterization instruments.

\begin{tabular}{ccc}
\hline Instrument & Model & Manufacturer \\
\hline SEM & TESCAN MIRA3 & Tesken Trading Co., Ltd., Shanghai, China \\
FT-IR & VERTEX70 & Swiss Brook \\
XRD & D/MAX-2500/PC & Nippon Neotoku Corporation \\
Zeta potential & Zetasizer Nano S90 & Malvern Instrument Co. Ltd., Worcestershire, UK \\
PPMS-VSM & PPMS-9 & Quantum Design, San Diego, CA, USA \\
\hline
\end{tabular}

\subsection{Adsorption Experiment}

To study the adsorption behavior of GOH/DCS and GOH/DMCS, several groups of $25 \mathrm{~mL}$ and $25 \mathrm{mg} / \mathrm{L}$ of rare earth $\mathrm{La}(\mathrm{III})$ solutions were taken, and the effects of diatomite dosage, adsorption time, $\mathrm{pH}$ value, adsorption temperature, adsorbent dosage, and initial concentration of $\mathrm{La}$ (III) solution on the adsorption of $\mathrm{La}(\mathrm{III})$ by composite materials were studied. Next, a filter with a $0.45-\mu \mathrm{m}$ pore size and the absorbance of the filtered supernatant with arsenazo III spectrophotometer was measured, the adsorption efficiency $(w)$ and adsorption capacity $\left(q_{e}\right)$ were calculated, and the $\mathrm{pH}$ value of each suspension with hydrochloric acid and sodium hydroxide was controlled.

The equilibrium adsorption capacity $\left(q_{e}\right)$ and adsorption rate $(w)$ of $\mathrm{La}(\mathrm{III})$ by GOH/DCS and GOH/DMCS were calculated according to Equation (1) and Equation (2), respectively.

$$
\begin{gathered}
q_{e}=\frac{\left(C_{0}-C_{e}\right) V}{m} \\
w=\frac{\left(C_{0}-C_{e}\right)}{C_{0}} \times 100 \%
\end{gathered}
$$

where $q_{e}$ is the adsorption capacity $(\mathrm{mg} / \mathrm{g}) ; C_{0}$ is the initial concentration of the solution, $\mathrm{mg} / \mathrm{L} ; C_{e}$ is the concentration of $\mathrm{La}(\mathrm{III})$ in the solution after adsorption equilibrium, $\mathrm{mg} / \mathrm{L}$; $\mathrm{V}$ is the liquid volume, $\mathrm{mL} ; \mathrm{m}$ is the amount of adsorbent $(\mathrm{mg})$; and $w$ is the adsorption rate $(\%)$.

Magnetic separation was carried out on the adsorption saturated GOH/DMCS composite material from the solution. Then, it was placed in $0.2 \mathrm{~mol} / \mathrm{L} \mathrm{HNO}_{3}$ desorption solution, at room temperature of $25^{\circ} \mathrm{C}$, oscillating frequency of $250 \mathrm{r} / \mathrm{min}$, oscillating for $\mathrm{t}$ min to desorb until desorption equilibrium. Then, the absorbance of filtered supernatant was measured by arsenazo III spectrophotometer, and the desorption rate was calculated. The GOH/DMCS composite material after magnetic separation is cleaned to neutrality by deionized water many times, dried in an oven at $60^{\circ} \mathrm{C}$, and the above adsorption-desorption experimental operation is continuously circulated.

According to Equation (3), the desorption rate of rare earth element La(III) by GOH/DMCS was calculated.

$$
R_{d}=\frac{V C_{e}^{\prime}}{M q_{e}} \times 100 \%
$$

where $R_{d}$ is the desorption rate, \%; $C_{e}^{\prime}$ is the concentration of $\mathrm{La}(\mathrm{III})$ in the desorbed solution, $\mathrm{mg} / \mathrm{L} ; \mathrm{V}$ is the volume of liquid, $\mathrm{L} ; M$ is the amount of adsorbent $(\mathrm{g})$; and $q_{e}$ is the adsorption capacity $(\mathrm{mg} / \mathrm{g})$. 
2.5. Adsorption Kinetics, Adsorption Isotherms, and Adsorption Thermodynamics Experiments

\subsubsection{Adsorption Kinetics}

In order to quantify the change law of adsorption with time, describe the solute absorption rate, and reveal the mechanism involved in the adsorption process, the experimental data are processed by pseudo-first order kinetics, pseudo-second order kinetics, and internal diffusion model equations, which are as follows [15]:

$$
\begin{gathered}
\ln \left(q_{e}-q_{t}\right)=\ln q_{e}-k_{1} t \\
\frac{t}{q_{t}}=\frac{1}{q_{e}^{2} k_{2}}+\frac{t}{q_{e}} \\
q_{t}=k_{d} t^{1 / 2}+C
\end{gathered}
$$

where $t(\mathrm{~min})$ is the adsorption time, $q_{e}\left(\mathrm{mg} \cdot \mathrm{g}^{-1}\right)$ and $q_{t}\left(\mathrm{mg} \cdot \mathrm{g}^{-1}\right)$ are the equilibrium adsorption capacity and adsorption capacity at time $\mathrm{t}$, respectively. $k_{1}\left(\mathrm{~min}^{-1}\right), k_{2}\left(\mathrm{~g} \cdot(\mathrm{mg} \cdot \mathrm{min})^{-1}\right)$, and $k_{d}\left(\mathrm{mg} \cdot \mathrm{g}^{-1} \cdot \mathrm{min}^{-1 / 2}\right)$ are the pseudo-first order kinetics, pseudo-second order kinetics, and diffusion rate constants in particles, respectively. $C$ is the boundary layer constant.

\subsubsection{Adsorption Isotherm}

Adsorption isotherm study is of great significance to determine the adsorption capacity of La(III) on modified GOH/DMCS composites. Langmuir and Freundlich isotherm models are used to analyze adsorption data [16].

The linear equations of Langmuir and Freundlich isothermal models are as follows:

$$
\begin{gathered}
\frac{C_{e}}{q_{e}}=\frac{C_{e}}{q_{m}}+\frac{1}{q_{m} \cdot K_{L}} \\
\ln q_{e}=\ln K_{F}+\frac{1}{n} \ln C_{e}
\end{gathered}
$$

where $C_{e}\left(\mathrm{mg} \cdot \mathrm{L}^{-1}\right)$ is the concentration of $\mathrm{La}(\mathrm{III})$ at adsorption equilibrium, $q_{e}\left(\mathrm{mg} \cdot \mathrm{g}^{-1}\right)$ is the adsorption capacity at adsorption equilibrium, $q_{m}$ is the maximum adsorption capacity $\left(\mathrm{mg} \cdot \mathrm{g}^{-1}\right), K_{L}$ is the Langmuir constant $\left(\mathrm{L} \cdot \mathrm{mg}^{-1}\right)$ and $K_{F}$ is the Freundlich constant $\left(\mathrm{mg} \cdot \mathrm{g}^{-1}\right)$

The dimensionless parameter $R_{L}$ can further analyze the adsorption process. When $R_{L}=0$, the adsorption process is irreversible. When $R_{L}=0 \sim 1$, the adsorption process is favorable. When $R_{L}>1$, it is unfavorable for adsorption. The calculation formula is as follows:

$$
R_{L}=\frac{1}{1+C_{0} K_{L}}
$$

where $C_{0}$ is the initial concentration of solution, $\mathrm{mg} / \mathrm{L}$.

\subsubsection{Adsorption Thermodynamics}

Adsorption thermodynamics uses three calculated thermodynamic parameters, namely Gibbs free energy change $\left(\Delta G^{0}\right)$, enthalpy change $\left(\Delta H^{0}\right)$, and entropy change $\left(\Delta S^{0}\right)$, to study the degree and driving force of adsorption process. Gibbs energy change $\left(\Delta G^{0}\right)$ indicates the degree of spontaneity in the adsorption process, while the higher negative value reflects that it is more beneficial to adsorption in the adsorption process. Enthalpy change $\left(\Delta H^{0}\right)$, which is the change of enthalpy of an object, is a thermodynamic energy state function, which indicates that the adsorption process belongs to endothermic or exothermic reaction. Entropy change $\left(\Delta S^{0}\right)$ reflects the disorder or disorder degree of the interface between solid and solution during adsorption [17].

$\Delta H^{0}$ and $\Delta S^{0}$ are calculated by the van't Hoff Equation:

$$
\ln K_{d}=-\frac{\Delta H^{0}}{R T}+\frac{\Delta S^{0}}{R}
$$


where $K_{d}$ is dispersion coefficient, $\mathrm{L} / \mathrm{g} ; \Delta H^{0}$ is enthalpy change, $\mathrm{KJ} \cdot \mathrm{mol}^{-1}$; $\mathrm{R}$ is gas constant, $8.31 \times 10^{-3} \mathrm{KJ} \cdot \mathrm{mol}^{-1} \cdot \mathrm{k}^{-1}$; $\mathrm{T}$ is absolute temperature, $\mathrm{K}$; and $\Delta S^{0}$ is entropy change, $\mathrm{J} \cdot \mathrm{K}^{-1} \cdot \mathrm{mol}^{-1}$.

$\Delta G^{0}$ is calculated using the following Equation:

$$
\begin{gathered}
\Delta G^{0}=-R T \ln K_{d} \\
K_{d}=\frac{q_{e}}{C_{e}}
\end{gathered}
$$

Thereinto, the change of Gibbs free energy of $\Delta G^{0}$ is $\mathrm{KJ} \cdot \mathrm{mol}^{-1}$.

\section{Results and Discussion}

\subsection{Material Characterization}

As shown in Figure 1, the surface of GO (a) prepared by the improved Hummers' method was smooth, with an accumulated flaky structure and numerous wrinkles. Compared with the GO, the surface of GOH (b) was relatively rough, with numerous irregular wrinkles and cracks, which were possibly due to the activation of the epoxide and ester groups, and the conversion of hydroxyl groups $(-\mathrm{OH})$ into carboxyl groups $(-\mathrm{COOH})[18,19]$. As observed in the SEM image (c) of the pretreated DE, DE was discshaped with a smooth surface and regular porosity [20]. Many impurities were observed on the diatomite surface. Acidification pre-treatment was used to remove impurities and to better prepare adsorbents for integrating with the composite materials. Thus, the internal structure of CS (d) was solid and filamentous, with a relatively rough surface and porous structure. The SEM image of MCS (e) showed that the chitosan was grainy after magnetic modification, with agglomerated white round particles, and the diameter of the magnetic particles was about $30 \mathrm{~nm}$ [21]. In the SEM image (f) of GOH/DCS, the interior of the modified adsorption material still showed the appearance of regular and large pores, thus increasing the specific surface area of the sheet structure. The increase in pore structure and the specific surface area provided a greater possibility for the adsorption of the rare earth La elements [22]. Furthermore, GOH/DMCS (g) had a fold on the porous disk structure, which differed from those on the DE surface, which was covered with a thick layer of folds, increasing the dispersity. This was attributed to the successful compounding of the carboxylated graphene oxide and modified materials. In addition, the apparent surface roughness of the intact DE structure, and the irregular adhesion of magnetic chitosan particles on the surface of the modified materials, confirmed the successful preparation of the magnetic chitosan/diatomite-modified carboxylated graphene oxide.

The infrared spectrograms of GO, GOH, DE, CS, GCS, GOH/DCS, and GOH/DMCS are shown in Figure 2. As shown in the FTIR spectrogram for GO in Figure 2a, the prominent peak at $3406 \mathrm{~cm}^{-1}$ corresponds to the asymmetric stretching vibration peak of $-\mathrm{OH}$, while the vibration at $1650 \mathrm{~cm}^{-1}$ was the stretching vibration peak of $\mathrm{C}=\mathrm{O}$ in the carboxyl group of $\mathrm{GO}$, and $\mathrm{C}=\mathrm{O}$ was grafted on the edge of $\mathrm{GO}$. The peak at $1507 \mathrm{~cm}^{-1}$ reflected the vibration absorption of the $\mathrm{C}=\mathrm{C}$ skeleton and the characteristic bending band of the $\mathrm{O}-\mathrm{H}$ bond in the undamaged aromatic region. The $\mathrm{C}-\mathrm{O}$ stretching vibration band and $\mathrm{C}-\mathrm{O}-\mathrm{C}$ vibration absorption band appeared at $1260 \mathrm{~cm}^{-1}$ [23]. Many oxygen-containing functional groups appeared in the interlayer and edge of GO, and the above conclusions indicated that GO was successfully prepared by the modified Hummers' method. For GOH, the FTIR spectrum shows characteristic bands for GO, and a characteristic peak at $1171 \mathrm{~cm}^{-1}$ was attributed to the antisymmetric tensile vibration of $\mathrm{C}-\mathrm{O}-\mathrm{C}$. Compared with $\mathrm{GO}$, the characteristic bending of the $\mathrm{O}-\mathrm{H}$ bond and the stretching vibration of $\mathrm{C}-\mathrm{O}$ for the carboxyl group also appeared at $1600 \mathrm{~cm}^{-1}$. The prominent stretching vibration of $-\mathrm{OH}$ in GO shifted from $3406 \mathrm{~cm}^{-1}$, and a less obvious peak appeared at $3419 \mathrm{~cm}^{-1}$ in the FTIR spectrum of $\mathrm{GOH}$, indicating that the carboxyl groups in the alkaline environment replaced some hydroxyl groups in GO. Thus, the FTIR results confirmed the successful preparation of GOH. In the FTIR spectrum of DE Figure $2 b$, the peak at $3434 \mathrm{~cm}^{-1}$ was attributed to the stretching vibration of the free silanol group $(\mathrm{Si}-\mathrm{OH})$. In addition, the bands at $1613 \mathrm{~cm}^{-1}$ 
and $1525 \mathrm{~cm}^{-1}$ were related to the bending vibrations of water molecules $(\mathrm{H}-\mathrm{O}-\mathrm{H})$ [24]. The band at $1090 \mathrm{~cm}^{-1}$ reflected the stretching of the siloxane $(\mathrm{Si}-\mathrm{O}-\mathrm{Si}$ ) group, while 849 and $792 \mathrm{~cm}^{-1}$ were associated with $\mathrm{Si}-\mathrm{O}$ tension and $\mathrm{SiO}-\mathrm{H}$ vibrations. The peak at 572 $\mathrm{cm}^{-1}$ reflected the stretching vibration of $\mathrm{Si}-\mathrm{O}-\mathrm{Si}[25,26]$. In the FTIR spectrum of CS (c), there were apparent $-\mathrm{OH}$ asymmetric stretching vibrations at $3437 \mathrm{~cm}^{-1}$ and $\mathrm{N}-\mathrm{H}$ stretching vibrations for the absorption peak on $-\mathrm{NHCO}-$. A C $-\mathrm{H}$ stretching vibration appeared at $2992 \mathrm{~cm}^{-1}$, and at $1603 \mathrm{~cm}^{-1}$, the stretching vibration of the alcohol hydroxyl group $\mathrm{C}=\mathrm{O}$ from $-\mathrm{NHCO}-$ occurred. The peak at $1514 \mathrm{~cm}^{-1}$ was related to the $\mathrm{N}-\mathrm{H}$ stretching vibration of $-\mathrm{NH}_{2}$, and a $\mathrm{C}-\mathrm{H}$ absorption peak appeared at $1428 \mathrm{~cm}^{-1}$. The absorption peak at $1078 \mathrm{~cm}^{-1}$ was attributed to the stretching vibration of $\mathrm{C}-\mathrm{O}$. [27] The FTIR spectrum of MCS showed that the characteristic peak at $580 \mathrm{~cm}^{-1}$ was $\mathrm{Fe}_{3} \mathrm{O}_{4}$, which indicated that the magnetic particles were successfully loaded. The hydroxyl peak intensity at $3437 \mathrm{~cm}^{-1}$ on CS weakened and moved to the left to $3429 \mathrm{~cm}^{-1}$, which was possibly caused by the interactions between nano-ferric oxide particles and chitosan functional groups during magnetization.
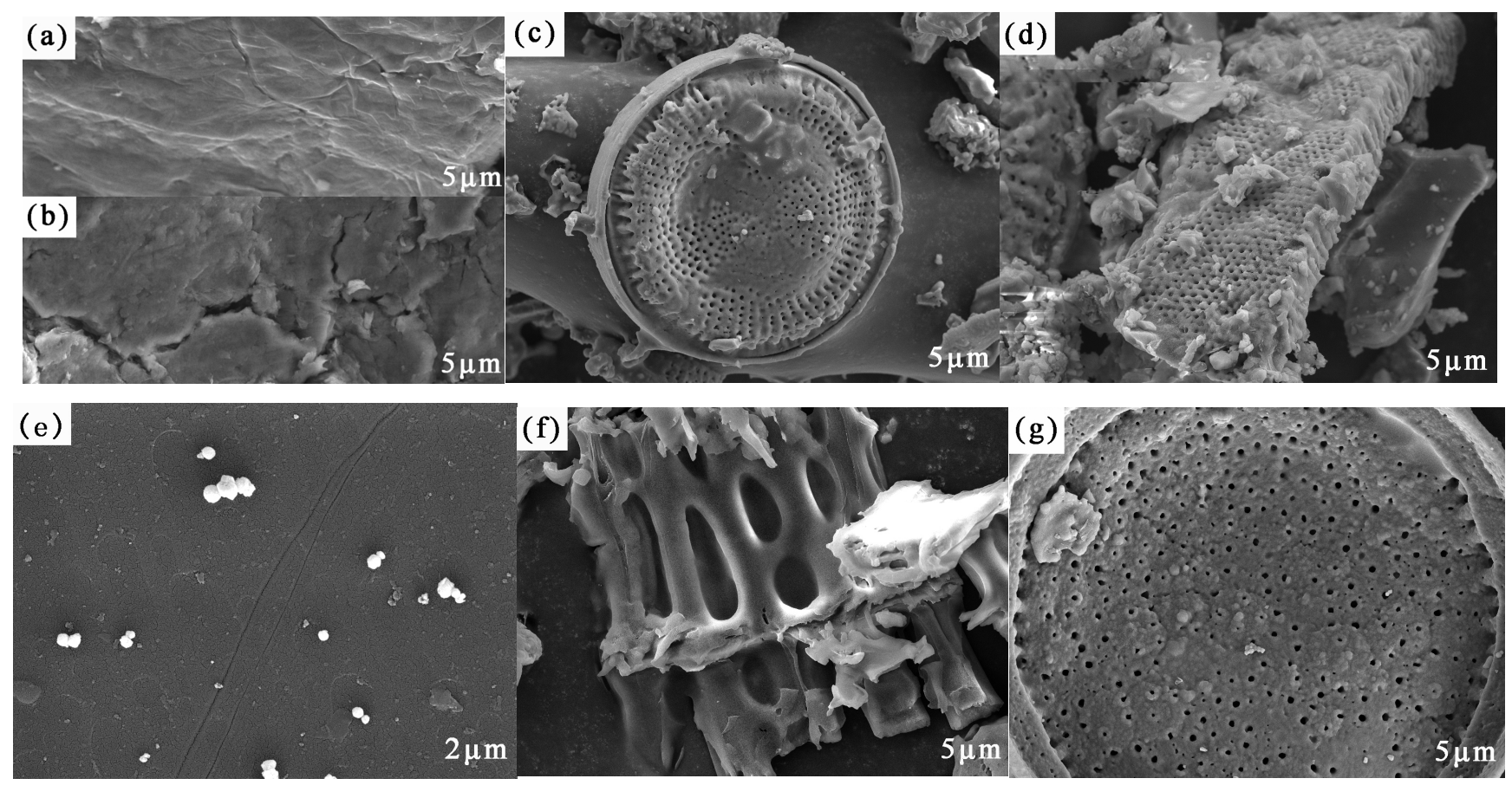

Figure 1. SEM images of (a) GO, (b) GOH, (c) DE, (d) CS, (e) MCS, (f) GOH/DCS, and (g) GOH/DMCS.

In the FTIR spectrum of GOH/DCS (d), the characteristic peaks of DE and CS appeared beside the characteristic peaks of the carboxyl group. The appearance of NH stretching and the characteristic peak of the amide group at $1612 \mathrm{~cm}^{-1}$ indicated that chitosan was successfully grafted onto the GOH molecule [28]. The typical band of the chitosan polymer $(\mathrm{OH})$ appeared at $3410 \mathrm{~cm}^{-1}$. In addition, $2813 \mathrm{~cm}^{-1}$ corresponded to the $\mathrm{C}-\mathrm{H}$ tensile absorption band. The modified infrared band was wider and stronger, which indicated that GOH/DCS carried more chitosan. The band at $1090 \mathrm{~cm}^{-1}$ reflected the stretching of the siloxane ( $\mathrm{Si}-\mathrm{O}-\mathrm{Si}$ ) group in DE. Thus, an $\mathrm{SiO}-\mathrm{H}$ vibration peak appeared at $786 \mathrm{~cm}^{-1}$.

In summary, the GOH/DCS materials were successfully modified and prepared. In the FTIR spectrum of GOH/DMCS, a shift in the $\mathrm{OH}$ stretching vibration peak of the carboxyl group appeared at $3421 \mathrm{~cm}^{-1}$, which indicated that hydrogen bonding occurred between the hydroxyl groups in each material. The other peaks at 786, 1090, and $1612 \mathrm{~cm}^{-1}$ corresponded to the FTIR spectra of DE. Thus, the modification of the carboxylated graphene oxide/diatomite composite did not change the functional group structure of DE, and GOH covered the surface of DE through covalent bonding. Additionally, the carboxyl groups 
in the carboxylated graphene oxide and original graphene oxide were successfully compounded with GCS through covalent bonding. The electron micrographs also showed that the composite modified by GOH/DMCS retained the DE structure, which was consistent with the obtained FTIR results. Therefore, the excellent properties of DE, such as numerous pores, large specific surface area, and strong adsorption capacity, were retained when the composite was successfully prepared.
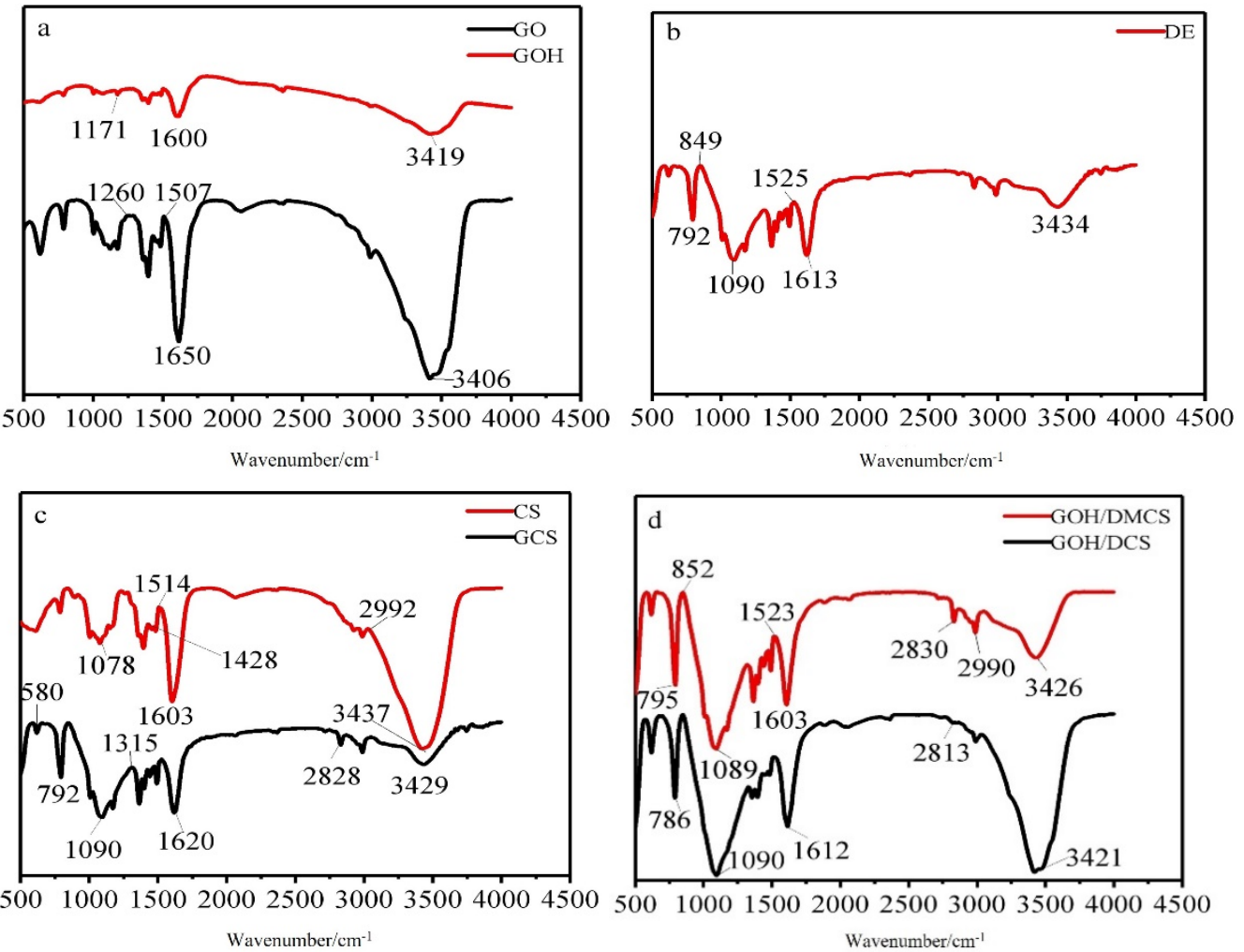

Figure 2. FTIR spectra of (a) GO and (GOH), (b) DE, (c) CS and MCS, and (d) GOH/DCS and GOH/DCS.

The crystal structure changes in each sample were analyzed by XRD, and the XRD analysis results of GO, GOH, CS, GOH/DCS, DE, and GOH/DMCS are shown in Figure 3. The diffraction peak of the (d001) crystal plane appeared in the GO (a), which was prepared by the improved Hummers' method at $2 \theta=10.9$, according to Bragg formula $(2 \mathrm{~d} \sin \theta=\mathrm{n} \lambda)$, with an interlayer spacing of $0.81 \mathrm{~nm}$. In the XRD results for $\mathrm{GOH}$, the diffraction peak appeared at $2 \theta=10.6$, and the interlayer spacing was $0.83 \mathrm{~nm}$, which indicated that the diffraction peak of the same crystal plane shifted to a low angle. The calculated results showed that the introduction of chloroacetic acid increased the interlayer spacing of $\mathrm{GOH}$, and a dense layered graphene oxide structure was layered into the disordered sheets of $\mathrm{GOH}$. In addition, carboxylation treatment increased the number of -COOH groups at the edge and interlayers of GO. In the XRD results of CS, (b) the characteristic peak of the amorphous chitosan structure appeared at $2 \theta=19.92$, and the diffraction peak of the $\mathrm{GOH} / \mathrm{DCS}$ composite decreased to $2 \theta=21.81$, indicating that the CS crystal phase content declined. Then, the diffraction peak of $\mathrm{GOH}$ appeared again, and the diatomite diffraction peak appeared at $2 \theta=36.09$. The analysis results showed that $\mathrm{GOH}$ was related to DE and CS. In $\mathrm{DE}(\mathrm{c})$ and $\mathrm{GOH} / \mathrm{DMCS}$, the diffraction peaks were very similar, indicating that silicon dioxide accounted for a large proportion of DE. The diffraction peak of magnetic ferric oxide simultaneously appeared, verifying the successful preparation of the magnetic graphene oxide-based composites. 

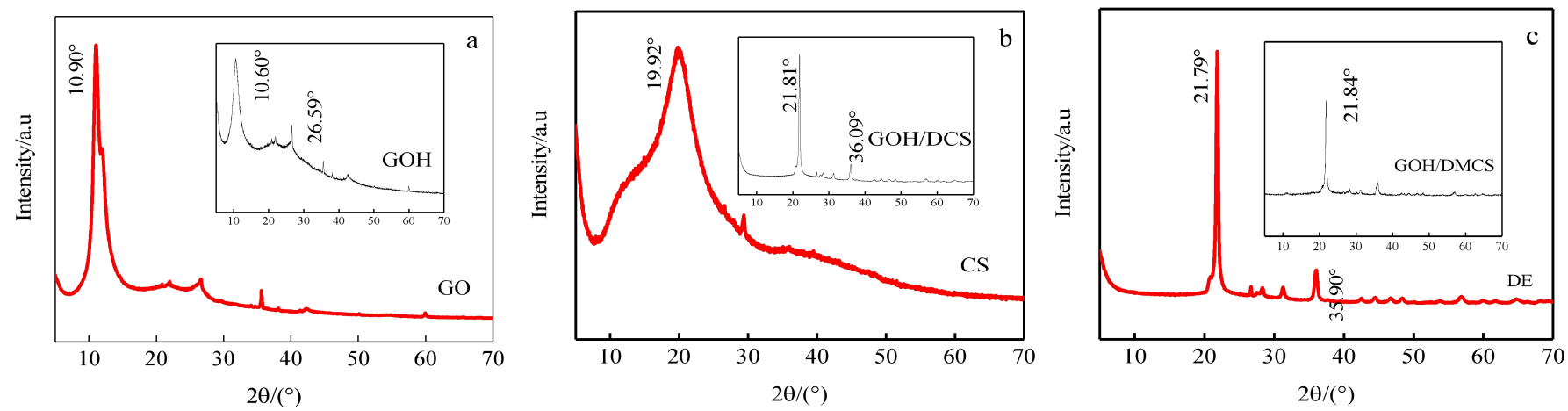

Figure 3. XRD patterns of the different materials: (a) GO and GOH, (b) CS and GOH/DCS, and (c) DE and GOH/DMCS.

In this work, the zeta potential of GOH/DMCS in the water phase was measured using a Zetasizer Nano 590 potential analyzer from the Malvern company, in a 2-12 $\mathrm{pH}$ environment. The zeta potential results of GOH/DMCS are shown in Figure 4. The figure shows that the electronegativity of the GOH/DMCS surface gradually increased from acidic to alkaline with changes in $\mathrm{pH}$, from $-11.9 \mathrm{mV}$ at $\mathrm{pH}=2$ to $-30.4 \mathrm{mV}$ at $\mathrm{pH}=12$. In addition, compared to a potential value of $-9.5 \mathrm{mV}$ when the $\mathrm{pH}$ of graphene oxide was 2, the electronegativity of the GOH/DMCS surface was enhanced by the oxygencontaining functional groups, which were ionized as they were exposed to electricity in the aqueous solution.

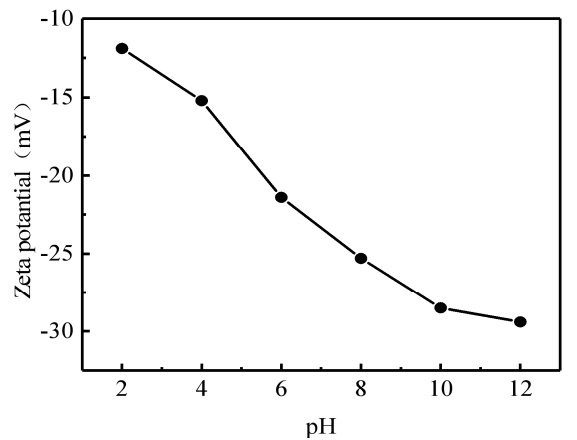

Figure 4. Zeta potential diagram of GOH/DMCS.

As shown from the negative zeta potential results under acid and alkaline conditions, the entire surface of the material became negatively charged, which was beneficial for the adsorption of positively charged rare earth $\mathrm{La}^{3+}$ elements. The negative charge density on the GOH/DMCS surface also increased with increased $\mathrm{pH}$, and the sol stability of the composite material also increased. This did not cause aggregation when in solution form.

As observed in the hysteresis curve (Figure 5), the hysteresis loop of the GOH/DMCS composite was S-shaped with an asymmetrical origin, and there was no obvious hysteresis loop. The maximum magnetization of the GOH/DMCS composite was $13.1 \mathrm{emu} / \mathrm{g}$, which was lower than the magnetization of $\mathrm{Fe}_{3} \mathrm{O}_{4}$ by $52.70 \mathrm{emu} / \mathrm{g}$ [29]. This was possibly due to the combination of $\mathrm{GOH}, \mathrm{DE}$, and CS non-magnetic materials, and the nanostructure of $\mathrm{Fe}_{3} \mathrm{O}_{4}$ during the preparation of the modified material, which weakened the magnetization of the composite material. However, the experimental diagram also showed that the ultrasonically dispersed uniform GOH/DMCS composite water solvent could be effectively separated in the aqueous solution in less than one minute, under an applied magnetic field. Thus, the above characterization results indicated that the GOH/DMCS composite was successfully prepared and could be used as an adsorbent that can be quickly separated and recovered. 


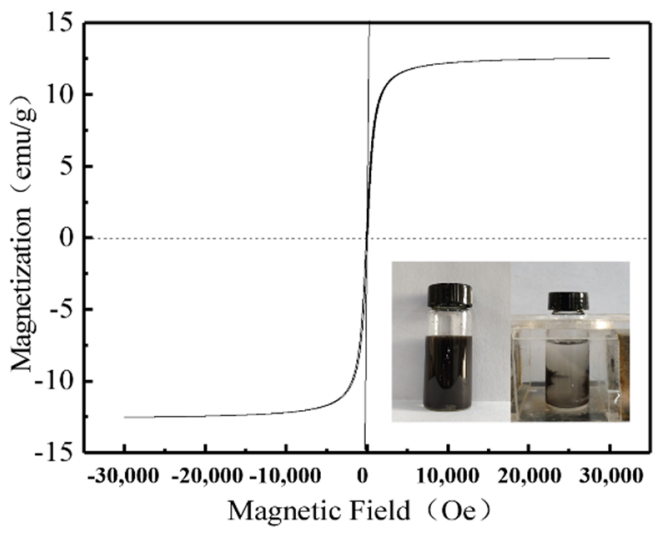

Figure 5. Magnetic hysteresis loops of GOH/DMCS.

\subsection{Adsorption and Desorption Properties of La (III) by GOH-Based Composites}

In this paper, compounding MCS not only changes the hydrophilicity of GO but also increases the number of functional groups $\left(-\mathrm{COOH},-\mathrm{OH},-\mathrm{O}-,-\mathrm{NH}_{2}\right.$, etc. $)$ on the surface of composite materials. There are many oxygen-containing functional groups, hydroxyl bridges, and carboxyl groups on the surface of GOH/DCS and GOH/DMCS composites, which make the whole composites have a lot of negative charges, which can interact electrostatically with positively charged rare earth elements, and they may also have complexation and chelation to achieve the removal effect. The adsorption and desorption properties of composite materials for lanthanum will be discussed below.

\subsubsection{Diatomite Content and the Influence of Different Materials on Adsorption}

DE content in composite materials can directly affect the adsorption effects of La(III). Therefore, GOH/DCS and GOH/DMCS composite materials were prepared with different diatomite addition amounts. Specifically, 1, 2, 3, 4, and $5 \mathrm{~g}$ adsorption experiments were carried out on the target pollutant La(III). Additionally, adsorption experiments for $\mathrm{La}$ (III) were carried out with GO and GOH matrix materials. The adsorption effects of the different materials were studied, and the results are shown in Figure 6.
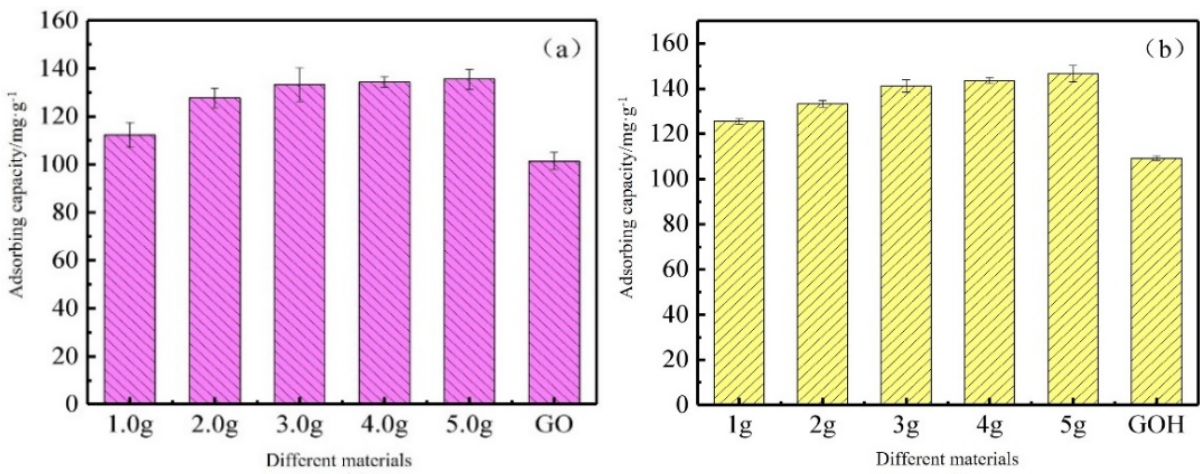

Figure 6. DE content and influence of different materials on adsorption: (a) GOH/DCS and GO adsorbing $\mathrm{La}(\mathrm{III})$, and (b) GOH/DMCS and GOH adsorbing $\mathrm{La}(\mathrm{III}) .\left(\mathrm{pH}=8, \mathrm{t}=50 \mathrm{~min}, \mathrm{~T}=45^{\circ} \mathrm{C}\right.$, $\mathrm{La}(\mathrm{III})$ concentration $=25 \mathrm{mg} \cdot \mathrm{L}^{-1}$, Dosage $=1 \mathrm{~g} \cdot \mathrm{L}^{-1}$ )

As shown in Figure 6, with increased addition of DE, the adsorption trend of the target pollutant $\mathrm{La}(\mathrm{III})$ by the composite GOH/DMCS and GOH/DCS material was roughly the same, with an apparent initial increase, which later slowed. The reason for this was due to GOH, which played a significant role in $\mathrm{La}$ (III) adsorption with small amounts of DE. With increasing DE content, its specific surface area, porous structure, and functional groups all participated in the reaction process and increased the number of adsorption sites for the adsorbent; thus, the adsorption capacity increased significantly. Therefore, 
the composite adsorbents used in the follow-up research were all prepared using $3 \mathrm{~g}$ of DE. Meanwhile, as observed from the adsorption capacity in the Table 2, the adsorption capacities of $\mathrm{La}$ (III) by GOH/DMCS, GOH/DCS, GOH, and GO were 146.58, 135.53, 109.23, and $101.37 \mathrm{mg} / \mathrm{g}$, respectively. The adsorption capacities of the prepared graphene oxide composites were higher than those of $\mathrm{GO}$ and $\mathrm{GOH}$. Thus, for the adsorption results, the modified composites had a better adsorption effect on $\mathrm{La}(\mathrm{III})$.

Table 2. Adsorption capacity of different materials under the same conditions.

\begin{tabular}{ccccc}
\hline Material & GO & GOH & GOH/DCS & GOH/DMCS \\
\hline Adsorption capacity $\left(\mathrm{mg} \cdot \mathrm{g}^{-1}\right)$ & 101.37 & 109.23 & 135.53 & 146.58 \\
\hline
\end{tabular}

\subsubsection{Influence of Adsorption Time on Adsorption and Kinetics}

As shown in Figure 7, the adsorption trends of the target pollutant $\mathrm{La}$ (III) by GOH/DMCS and GOH/DCS were similar. The adsorption of La (III) by GOH/DMCS reached adsorption equilibrium within $60 \mathrm{~min}$ when the adsorption capacity was $141.19 \mathrm{mg} / \mathrm{g}$. The adsorption of $\mathrm{La}$ (III) by GOH/DCS occurred within 50 min when the adsorption capacity was $134.23 \mathrm{mg} / \mathrm{g}$. Within $60 \mathrm{~min}$, the adsorption capacity increased rapidly; then, it reached adsorption equilibrium. The adsorption capacity of GOH/DMCS for La(III) was significantly higher than that of GOH/DCS, as during the initial period of adsorption, there were a sufficient number of exposed adsorption sites on the surface of the adsorbent. The negative charge on the surface of the adsorbent and the positively charged metal ions caused electrostatic interactions, and $\mathrm{La}(\mathrm{III})$ began to occupy the adsorption sites on the surface of the adsorbent. Thus, the adsorption capacity showed a rapid upward trend during the initial stage. As the contact time increased, the adsorption sites on the composite adsorbent gradually filled, and the adsorption gradually reached equilibrium. Thus, the GOH/DMCS composite material with added magnetic chitosan had a higher adsorption capacity than GOH/DCS for $\mathrm{La}$ (III) due to its magnetic separation. Based on the above conclusions, $50 \mathrm{~min}$ was chosen as the best equilibrium reaction time for the follow-up study.

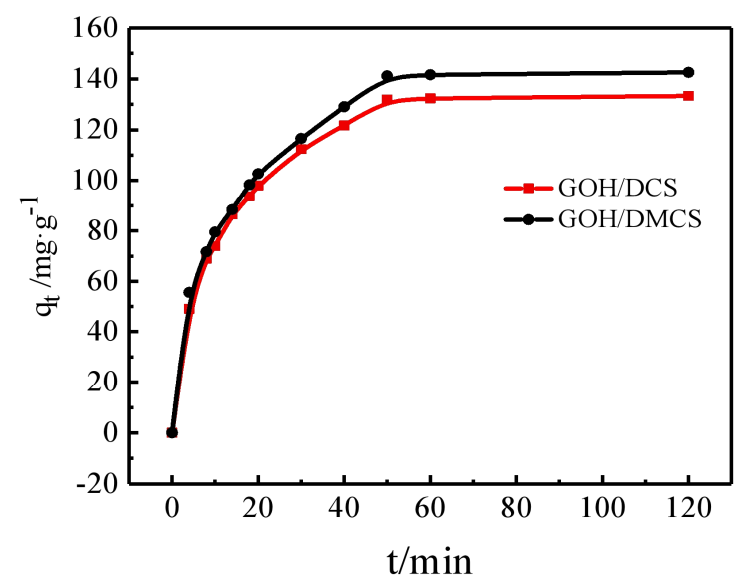

Figure 7. Influence of adsorption time on adsorption effect. $\left(\mathrm{pH}=8, \mathrm{~T}=45^{\circ} \mathrm{C}, \mathrm{La}\right.$ (III) concentration $=25 \mathrm{mg} \cdot \mathrm{L}^{-1}$, Dosage $=1 \mathrm{~g} \cdot \mathrm{L}^{-1}$ )

After studying the effect of adsorption time on the adsorption, we found it necessary to further explore the adsorption kinetics of GOH/DMCS on $\mathrm{La}(\mathrm{III})$. The fitting results of the kinetic model for GOH/DMCS adsorption of $\mathrm{La}(\mathrm{III})$ are shown in Figure 8, showing that more data points fell on the curve fitted by the pseudo-second-order kinetic model. As shown by the experimental parameters in Table 3, the correlation coefficient $\left(R^{2}\right)$ for $\mathrm{La}(\mathrm{III})$ adsorption described by the pseudo-second-order kinetic model was 0.9854 , which was higher than the correlation coefficient value of 0.9115 obtained by pseudo-first-order 
kinetics. Based on the above analysis results, we determined that the adsorption of La(III) on the GOH/DMCS composite material was best described by the pseudo-second-order kinetic model. The adsorption mechanism depended on the physical and chemical properties of the adsorbent and the chemical interactions of the adsorbent. Some scholars have found that the pseudo-second-order kinetic model indicates that most adsorption reactions are chemical rather than physical adsorption [30]. In addition, chemical adsorption was related to the sharing and transferring of electrons between the GOH composite material of GOH/DMCS and La(III). Thus, the initial reaction rate was calculated according to the following formula: $\mathrm{h}=\mathrm{k}_{2} \cdot \mathrm{q}_{\mathrm{e}}{ }^{2}$, where the initial reaction rate was $13.4590 \mathrm{mg} / \mathrm{g} \cdot \mathrm{min}$.

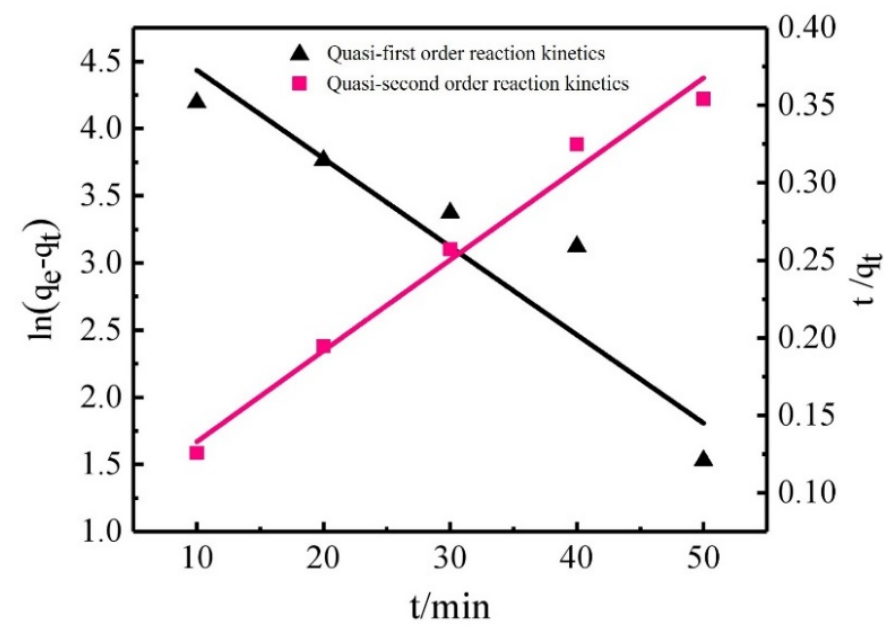

Figure 8. Kinetic model of La(III) adsorption by GOH/DMCS.

Table 3. Kinetic parameters of La(III) adsorption by GOH/DMCS.

\begin{tabular}{ccccccc}
\hline \multicolumn{2}{l}{ Quasi-First-Order Dynamics Model } & \multicolumn{5}{c}{ Quasi-Second-Order Dynamics Model } \\
\hline $\begin{array}{c}\mathrm{q}_{\mathrm{e}} \\
\mathrm{mg} / \mathrm{g}\end{array}$ & $\begin{array}{c}\mathrm{k}_{1} \\
\mathrm{~min}^{-1}\end{array}$ & $\mathrm{R}^{2}$ & $\begin{array}{c}\mathrm{h} \\
\mathrm{mg} /(\mathrm{g} \cdot \mathrm{min})\end{array}$ & $\begin{array}{c}\mathrm{q} \\
\mathrm{mg} / \mathrm{g}\end{array}$ & $\begin{array}{c}\mathrm{k}_{2} \\
\mathrm{~g} /(\mathrm{mg} \cdot \mathrm{min})\end{array}$ & $\begin{array}{c}\mathrm{R}^{2} \\
-\end{array}$ \\
\hline 162.77 & 0.0657 & 0.9115 & 13.4590 & 170.36 & $4.637 \times 10^{-4}$ & 0.9854 \\
\hline
\end{tabular}

To describe the diffusion of the system in a specific range, an internal diffusion model was used to fit the adsorption process, and the results are shown in Figure 9 and Table 4. As depicted in Figure 9, the straight line fitted by $\mathrm{q}_{\mathrm{t}}$ to $\mathrm{t}^{0.5}$ was divided into two sections, and the straight line did not pass through the origin, $C \neq 0$, indicating that the adsorption rate was not solely controlled by internal diffusion. Thus, for the adsorption process, the adsorbate underwent two main processes. In the first stage, the external diffusion of the adsorbate $\mathrm{La}(\mathrm{III})$ in the aqueous solution was adsorbed on the surface of the composite material by GOH/DMCS. In the second stage, internal diffusion of La(III) in GOH/DMCS occurred on the surface of the composite material or between the layers. From the adsorption parameters of the internal diffusion model, $\mathrm{k}_{\mathrm{d} 1}$ of the first stage was greater than $\mathrm{k}_{\mathrm{d} 2}$ of the second stage, which proved that the adsorption rate of GOH/DMCS for La(III) was higher in the initial period. 


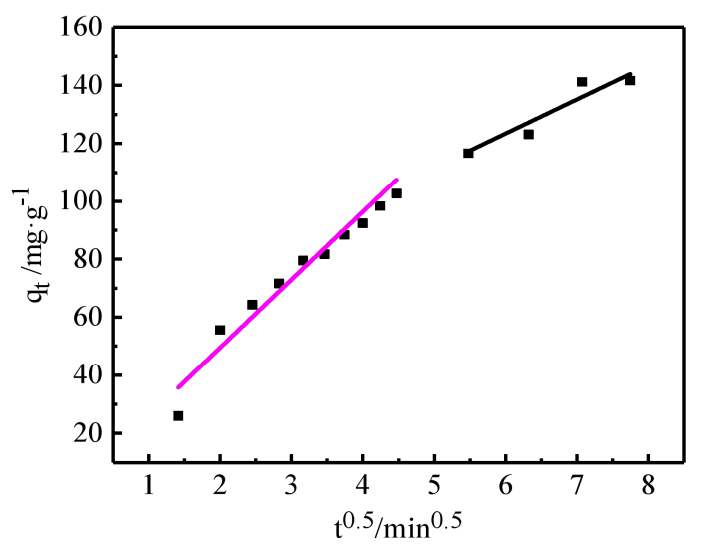

Figure 9. Intra-particle diffusion model of La(III) adsorption by GOH/DMCS.

Table 4. Intra-particle diffusion parameters of La(III) adsorption by GOH/DMCS.

\begin{tabular}{cccccc}
\hline \multicolumn{3}{c}{ First Stage } & \multicolumn{3}{c}{ Second Stage } \\
\hline $\mathrm{k}_{\mathrm{d} 1}$ & $\mathrm{C}_{1}$ & $\mathrm{R}^{2}$ & $\mathrm{k}_{\mathrm{d} 2}$ & $\mathrm{C}_{2}$ & $\mathrm{R}^{2}$ \\
$\mathrm{mg} \cdot \mathrm{g}^{-1} \cdot \mathrm{min}^{-1 / 2}$ & - & - & $\mathrm{mg} \cdot \mathrm{g}^{-1} \cdot \mathrm{min}^{-1 / 2}$ & - & - \\
\hline 23.4681 & 2.5361 & 0.9436 & 11.7543 & 52.9058 & 0.8288 \\
\hline
\end{tabular}

\subsubsection{Influence of $\mathrm{pH}$ Value of the Solution on Adsorption Effect}

In this portion of the study, the experiments were carried out at $\mathrm{pH} 2-12$, and the $\mathrm{pH}$ values were adjusted to 2, 4, 6, 8, 10, and 12 with $\mathrm{NaOH}$ or $\mathrm{HCl}$. As shown in Figure 10 that when the $\mathrm{pH}$ was 2, the adsorption capacity of GOH/DCS for $\mathrm{La}(\mathrm{III})$ was $98.97 \mathrm{mg} / \mathrm{g}$, and the adsorption rate was $65.98 \%$. The adsorption capacity of GOH/DMCS for $\mathrm{La}$ (III) was $109.18 \mathrm{mg} / \mathrm{g}$, and the adsorption rate was $72.78 \%$. The figure shows that with increased $\mathrm{pH}$, the adsorption rate rose, and the adsorption capacity of GOH/DMCS and GOH/DCS for the target $\mathrm{La}$ (III) pollutant initially increased. After the $\mathrm{pH}$ reached 8, the adsorption capacity was unchanged, and adsorption was optimal when $\mathrm{pH}$ was 8 . During this time, the adsorption capacities were 133.30 and $141.19 \mathrm{mg} / \mathrm{g}$, and the adsorption rates were 89 and $94 \%$.
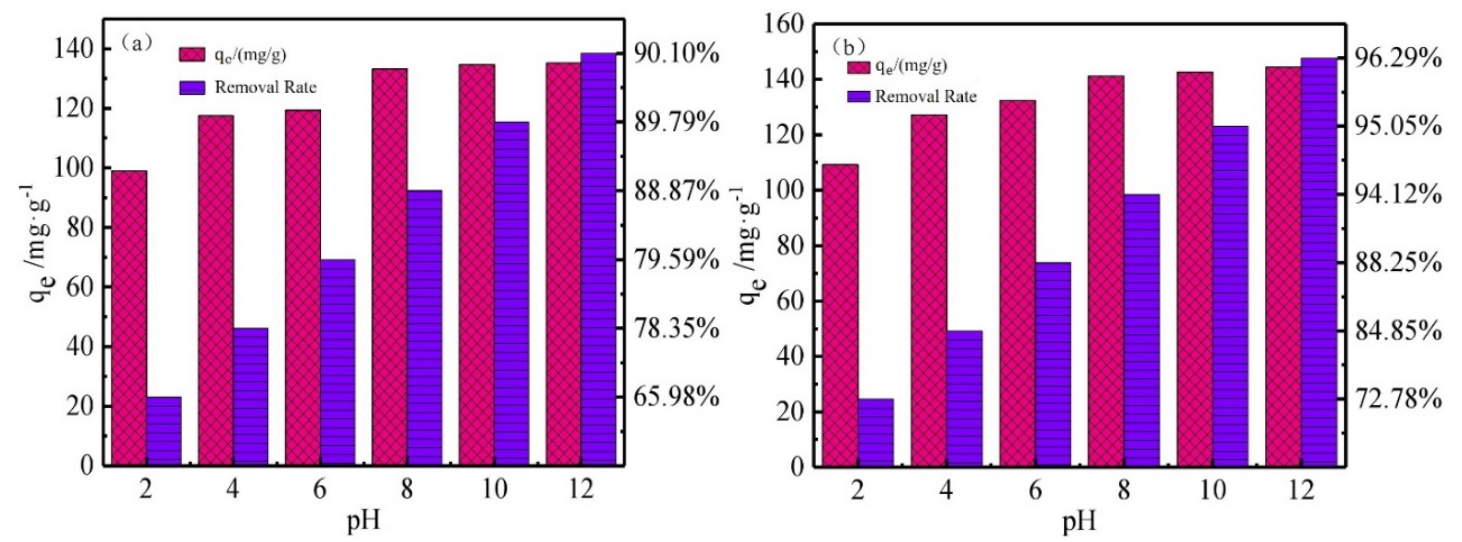

Figure 10. Influence of $\mathrm{pH}$ on the adsorption effects of $(\mathbf{a}) \mathrm{GOH} / \mathrm{DCS}$ and $(\mathbf{b}) \mathrm{GOH} / \mathrm{DMCS} .\left(\mathrm{t}=50 \mathrm{~min}, \mathrm{~T}=45^{\circ} \mathrm{C}, \mathrm{La}(\mathrm{III})\right.$ concentration $=25 \mathrm{mg} \cdot \mathrm{L}^{-1}$, Dosage $=1 \mathrm{~g} \cdot \mathrm{L}^{-1}$ )

The $\mathrm{pH}$ affected the positive and negative charges on the surface of the adsorbent and affected the presence of $\mathrm{La}(\mathrm{III})$ ions in the aqueous solution. When $\mathrm{pH}$ was 2, the zeta potential value of GOH/DMCS in the water phase was $-11.9 \mathrm{mV}$ (Figure 4). The surface of the composite adsorbent was negatively charged, and the $\mathrm{La}(\mathrm{III})$ ions were electrostatically 
attracted for removal. However, a large number of positively charged $\mathrm{H}+$ in the solution competed with the La(III) ions for adsorption sites on the adsorbent surface. Thus, due to the distribution of adsorption sites, the adsorption capacity was the lowest during this time. In addition, the GOH composite material had a high specific surface area and pore structure, which was conducive to adsorption.

Between pH 2 and 8, both the adsorption capacity and the adsorption rates trended upward, as shown in Figure 4, because the introduced oxygen-containing functional groups, $-\mathrm{COOH}$ and $-\mathrm{OH}$, ionized into $-\mathrm{COO}$ - and $-\mathrm{O}$ in the aqueous solution. Thus, the surface of the material became negatively charged, the electronegativity of the GOH/DMCS surface gradually increased with $\mathrm{pH}$ from acidic to alkaline, the zeta potential values of the GOH/DMCS surface accelerated in the negative direction, and the adsorption capacity of La(III) increased. Thus, both the capacity and the adsorption rate gradually increased, and GOH/DMCS adsorbed La(III) through complexation.

At $\mathrm{pH}>8, \mathrm{GOH} / \mathrm{DMCS}$ and GOH/DCS adsorbed and removed La (III) by forming a carboxylate complex. More $\mathrm{OH}^{-}$ions were present in the solution, and the rare earth cations and $\mathrm{OH}^{-}$ions combined, gradually becoming insoluble oxide and hydroxide precipitates. The precipitates hindered the adsorption of $\mathrm{La}(\mathrm{III})$, and the adsorption capacity was unchanged. According to the above analysis, the $\mathrm{pH}$ of the subsequent experiments was 8.

\subsubsection{Influence of Adsorbent Dosage on Adsorption Rate}

The adsorbent dosage curves are shown in Figure 11, indicating that the dosage of the adsorbent directly affected the adsorption of La(III) in the composite materials. When the dosage increased from 0.5 to $5 \mathrm{~g} / \mathrm{L}$, the adsorption rate increased, while the adsorption capacity declined. With increased adsorbent dosage, the number of active sites and functional groups in adsorbent gradually increased; therefore, there was a large contact area between the composite adsorbent and $\mathrm{La}(\mathrm{III})$, and the adsorption rate rose. However, the dosage effect of $5 \mathrm{~g} / \mathrm{L} \mathrm{GOH} / \mathrm{DCS}$ and GOH/DMCS was smaller than $0.5 \mathrm{~g} / \mathrm{L}$ of GOH/DCS and GOH/DMCS, and the higher adsorbent dosage caused an agglomeration of GOH/DCS and GOH/DMCS, resulting in a decrease in specific surface area. Thus, the adsorption capacity of GOH/DCS and GOH/DMCS for La(III) decreased with increased dosage.
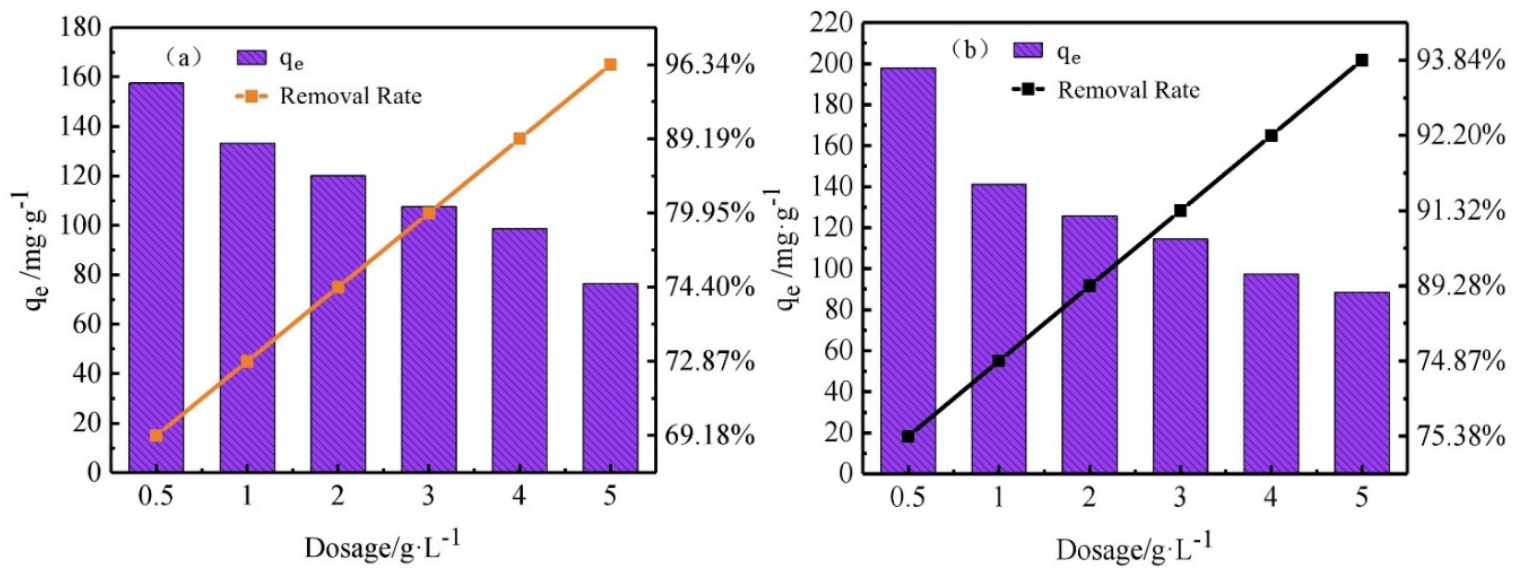

Figure 11. Influence of adsorbent dosage on adsorption for (a) GOH/DCS and (b) GOH/DMCS. ( $\mathrm{pH}=8, \mathrm{t}=50 \mathrm{~min}$, $\mathrm{T}=45^{\circ} \mathrm{C}, \mathrm{La}(\mathrm{III})$ concentration $=25 \mathrm{mg} \cdot \mathrm{L}^{-1}$ )

According to the analyzed data, the adsorption effect of GOH/DMCS on $\mathrm{La}$ (III) was better than that of GOH/DCS under the same dosage amount. GOH/DMCS had the highest adsorption rate of $\mathrm{La}(\mathrm{III})$, at $93.84 \%$, and the adsorption capacity was $197.94 \mathrm{mg} / \mathrm{g}$. The highest adsorption rate of $\mathrm{La}$ (III) by GOH/DCS was $96.34 \%$, and the adsorption capacity was $157.53 \mathrm{mg} / \mathrm{g}$. The adsorption capacity of GOH/DCS for La (III) was low, 
which was possibly because the $-\mathrm{COOH}$ at the edge of the carboxylated graphene oxide was more accessible and could more easily react and bond with $-\mathrm{NH}_{2}$ in the chitosan without magnetic modification. This effect may have affected the roles of these two functional groups during adsorption, thus resulting in lower adsorption capacity compared to $\mathrm{GOH} / \mathrm{DMCS}$.

3.2.5. Influence of Temperature and Initial Concentration of the Rare Earth Ion Solution on Adsorption

We also studied the effects of different initial concentrations and temperatures on adsorption efficiency. Figure 12 shows a changing trend in the adsorption effect of La (III) by $\mathrm{GOH} / \mathrm{DCS}$ and GOH/DMCS, which was similar at different temperatures. The adsorption capacities of GOH/DCS and GOH/DMCS for La (III) were 151.70 and $154.02 \mathrm{mg} / \mathrm{g}$ at $25^{\circ} \mathrm{C}$ and $30 \mathrm{mg} / \mathrm{L}$, respectively. When the temperature increased to $45^{\circ} \mathrm{C}$ and the solution concentration was $30 \mathrm{mg} / \mathrm{L}$, the adsorption capacities of GOH/DCS and GOH/DMCS for $\mathrm{La}(\mathrm{III})$ were 173.04 and $175.82 \mathrm{mg} / \mathrm{g}$, respectively. At the same initial concentration, when the temperature increased from 25 to $45^{\circ} \mathrm{C}$, the adsorption capacity trended upward, and the adsorption process was endothermic; thus, an increase in temperature was beneficial to the reaction. When the temperature rose, the movement of the rare earth La(III) ions on the surface of the composite adsorbent accelerated, collisions intensified, and the contact probability of the adsorbent increased; therefore, the adsorption capacity increased.
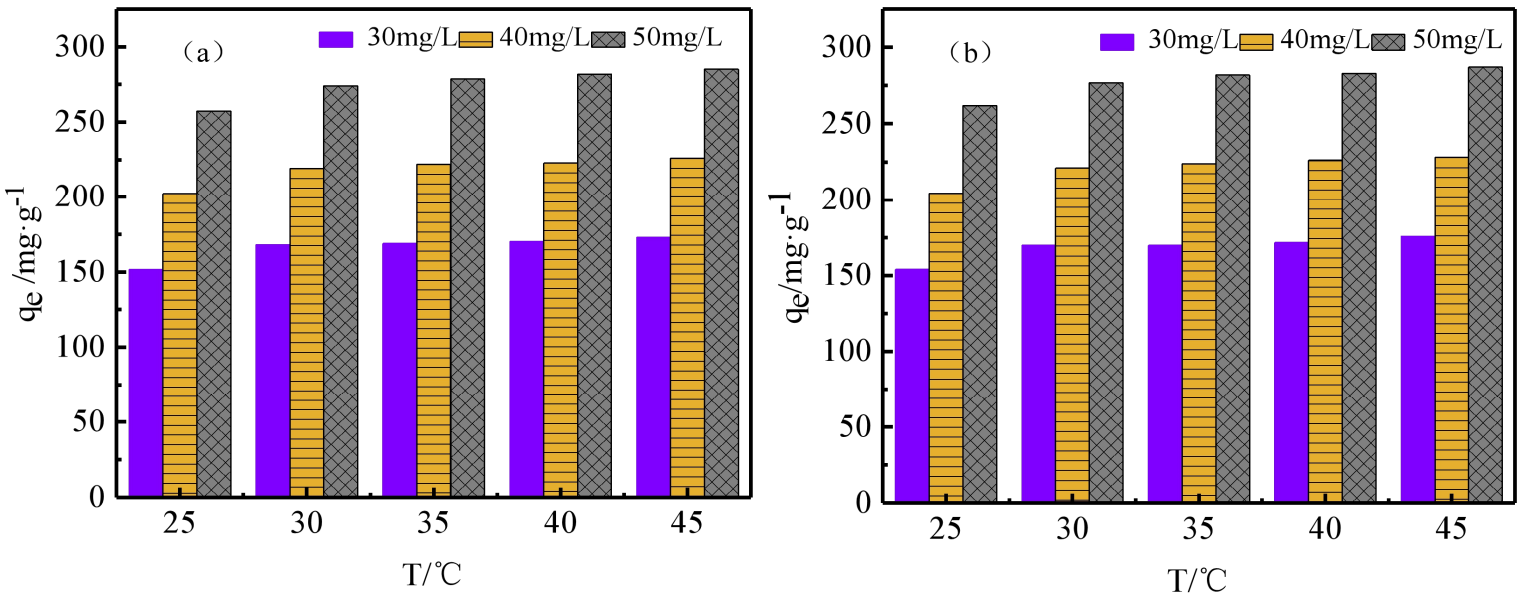

Figure 12. Influence of temperature and initial $\mathrm{La}(\mathrm{III})$ concentration on adsorption effect for (a) GOH/DCS and (b) GOH/DMCS $\left(\mathrm{pH}=8, \mathrm{t}=50 \mathrm{~min}\right.$, Dosage $\left.=3 \mathrm{~g} \cdot \mathrm{L}^{-1}\right)$.

At the same temperature, the initial concentration of the rare earth ion solution affected the adsorption and mass transfer processes, thus affecting the adsorption of La(III). As shown in Figure 12, the adsorption effects of GOH/DCS and GOH/DMCS on $\mathrm{La}$ (III) were the same at different initial solution concentrations. At $45{ }^{\circ} \mathrm{C}$, when the concentration increased from 30 to 40 , and then to $50 \mathrm{mg} / \mathrm{L}$, the adsorption capacity of $\mathrm{La}(\mathrm{III})$ by GOH/DMCS increased from 175.83 to 227.94 , and then to $287.01 \mathrm{mg} / \mathrm{g}$, respectively. With increased initial concentration, the adsorption capacity exhibited a gradual upward trend. However, the adsorption capacity of GOH/DMCS was slightly higher than the GOH/DCS composite, as the GOH/DMCS composite provided more adsorption sites for $\mathrm{La}$ (III) during the adsorption process. Of note, this also proved that the composite was successfully modified and prepared.

\subsubsection{Adsorption Isotherms}

Figure 13 shows the fitting results of the adsorption data for the GOH/DMCS composites using the Langmuir (a) and Freundlich models (b), and Table 5 lists the relevant parameters of the fitting results. As observed in the figure, most of the correlation points 
accurately fell on the linear fitting line in the Langmuir model. As listed in Table 4, the correlation coefficient $\left(\mathrm{R}^{2}\right)$ of the Langmuir model was higher than the fitting results of the Freundlich model; thus, the adsorption process of La(III) by GOH/DMCS was more in line with the Langmuir model, indicating that the adsorption process was attributable to monolayer adsorption. The surface contained a limited number of adsorption sites with uniform adsorption energies and with no migration of adsorbate on the surface [31,32]. According to the linear fitting line, the maximum adsorption capacity at 298 and $308 \mathrm{~K}$ reached 294.99 and $320.51 \mathrm{mg} / \mathrm{g}$, respectively. This was closer to the experimental values than the maximum adsorption capacity obtained by the Freundlich model. As observed from the dimensionless $\mathrm{R}_{\mathrm{L}}$ parameter in the Langmuir model (Table 6), which was between 0 and 1 at 298 and $308 \mathrm{~K}$, the adsorption of La(III) by GOH/DMCS was a favorable adsorption process, reflecting the high affinity between the adsorbent and adsorbate.
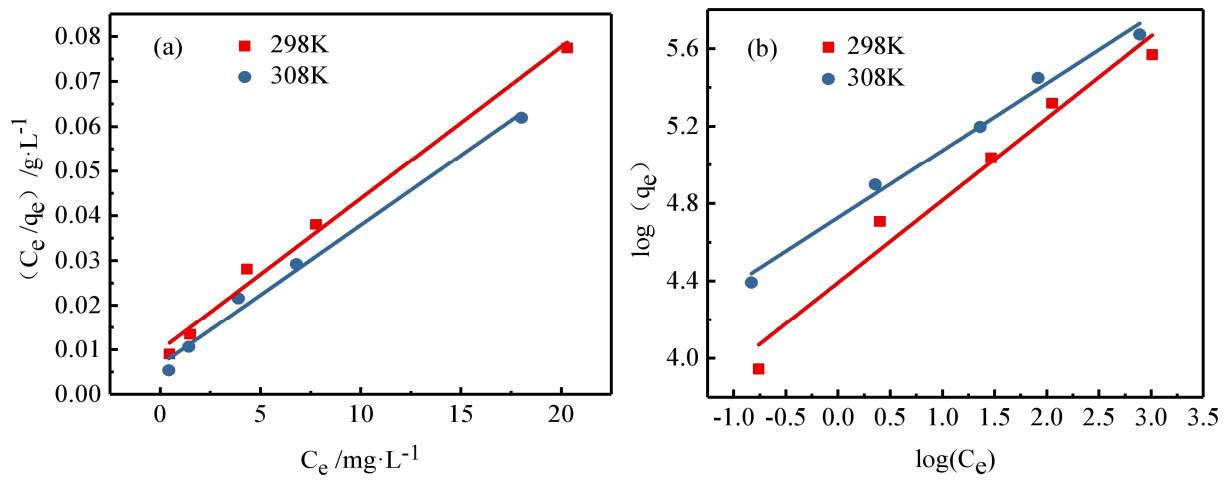

Figure 13. Isotherm models of La(III) adsorption by GOH/DMCS: (a) Langmuir model and (b) Freundlich model.

Table 5. Isothermal parameters of $\mathrm{La}(\mathrm{III})$ adsorption by GOH/DMCS.

\begin{tabular}{ccccccc}
\hline \multirow{2}{*}{ Temperature } & \multicolumn{3}{c}{ Langmuir Model } & \multicolumn{3}{c}{ Freundlich Model } \\
\cline { 2 - 7 } & $\mathbf{q}_{\mathbf{m a x}} / \mathbf{m g} \cdot \mathbf{g}^{-\mathbf{1}}$ & $\mathbf{K}_{\mathbf{L}} / \mathbf{L} \cdot \mathbf{m g}^{-\mathbf{1}}$ & $\mathbf{R}^{\mathbf{2}}$ & $\mathbf{K}_{\mathbf{F}} / \mathbf{m g} \cdot \mathbf{g}^{-\mathbf{1}} \cdot \mathbf{L}^{\mathbf{1 / n}} \cdot \mathbf{m g}^{-\mathbf{1} / \mathbf{n}}$ & $\mathbf{1 / n}$ & $\mathbf{R}^{\mathbf{2}}$ \\
\hline $298 \mathrm{~K}$ & 294.99 & 0.3407 & 0.9915 & 80.7784 & 0.4245 & 0.9681 \\
$308 \mathrm{~K}$ & 320.51 & 0.4692 & 0.9912 & 112.9652 & 0.3467 & 0.9890 \\
\hline
\end{tabular}

Table 6. Dimensionless parameter $\mathrm{R}_{\mathrm{L}}$.

\begin{tabular}{cc}
\hline Temperature & $\mathbf{R}_{\mathbf{L}}$ \\
\hline $298 \mathrm{~K}$ & $\sim 0.0554-0.2269$ \\
$308 \mathrm{~K}$ & $\sim 0.0409-0.1757$ \\
\hline
\end{tabular}

\subsubsection{Adsorption Thermodynamics}

As listed in Table 7 and Figure 14, the adsorption reaction enthalpy changes $\Delta \mathrm{H}^{0}>0$ indicated that the adsorption process of La(III) by GOH/DMCS was an endothermic reaction. As mentioned in the above results, the adsorption capacity increased when the temperature increased from 25 to $45^{\circ} \mathrm{C}$. Thus, the adsorption process was an endothermic reaction, and the temperature increase was beneficial to the progression of the reaction. The resulting enthalpy change was the same as that of temperature. At three different temperatures, 298, 303, and $308 \mathrm{~K}$, the Gibbs energy change $\left(\mathrm{G}^{0}\right)$ was less than 0 . As shown in Table 6 , the absolute value of $\mathrm{G}^{0}$ increased with increased temperature, indicating that the adsorption of $\mathrm{La}(\mathrm{III})$ by GOH/DMCS proceeded spontaneously. This also verified the improved adsorption effects at higher temperatures. The entropy change value $\left(\Delta S^{0}\right)$ was $50.0084 \mathrm{~J} \cdot(\mathrm{mol} \cdot \mathrm{k})^{-1}$, indicating that the disorder of the solid-liquid interface system increased during the adsorption of $\mathrm{La}(\mathrm{III})$ by the GOH/DMCS composite. This also 
indicated that when discrete rare-earth ions combine with adsorbents, more ions will be released during adsorption.

Table 7. Thermodynamic parameters of La(III) adsorption by GOH/DMCS.

\begin{tabular}{cccc}
\hline Temperature $(\mathbf{K})$ & $\boldsymbol{\Delta G}^{\mathbf{0}} / \mathbf{K J} \cdot \mathbf{m o l}^{-\mathbf{1}}$ & $\boldsymbol{\Delta} \mathbf{H}^{\mathbf{0}} / \mathbf{K J} \cdot \mathbf{m o l}^{-\mathbf{1}}$ & $\left.\boldsymbol{\Delta} \mathbf{S}^{\mathbf{0}} \mathbf{J} \cdot \mathbf{( m o l} \cdot \mathbf{K}\right)^{-\mathbf{1}}$ \\
\hline 298 & -5.5135 & 10.2943 & 50.0084 \\
303 & -5.7433 & 10.2943 & 50.0084 \\
308 & -6.0444 & 10.2943 & 50.0084 \\
\hline
\end{tabular}

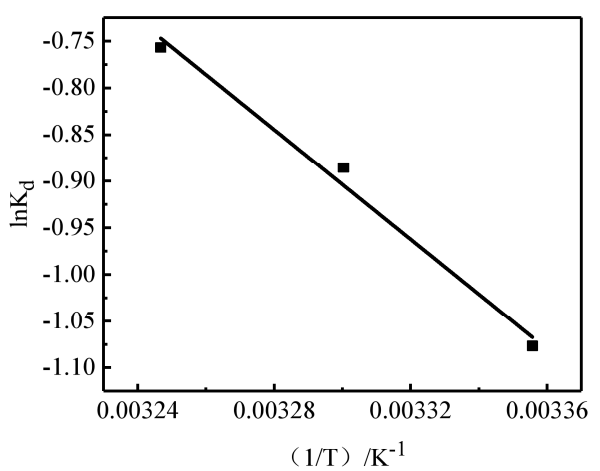

Figure 14. Thermodynamic model of La(III) adsorption by GOH/DMCS.

\subsection{Analysis of Desorption Results}

In practical applications, the disposal of nanomaterial (NMs) adsorbents used in adsorption processes negatively affects water quality; thus, reusability is a critical factor for creating suitable adsorbents. Desorption from adsorbents with a high affinity requires a high concentration of acid and/or chelating agents. In addition, desorption of La(III) from nanomaterials occurs in acidic solutions such as hydrochloric acid, nitric acid, or sulfuric acid. We determined that the GOH/DMCS composites prepared in this study achieved a separation effect under an external magnetic field due to their magnetism. Therefore, $0.2 \mathrm{~mol} / \mathrm{L}$ of $\mathrm{HNO}_{3}$ solution was used in this work for the desorption and adsorption-desorption cycling regeneration experiments.

As shown in Figure 15 that the adsorption capacities of the GOH/DMCS composites for $\mathrm{La}(\mathrm{III})$ exceeded $74 \%$ after four adsorption-desorption cycles, and the desorption percentage decreased only slightly after several adsorption-desorption cycles. This proved that the recycling of magnetic NMs can be simply and effectively achieved for adsorbent recycling, using external magnets. Of note, the gradual decrease in the desorption rate was possibly due to incomplete desorption.

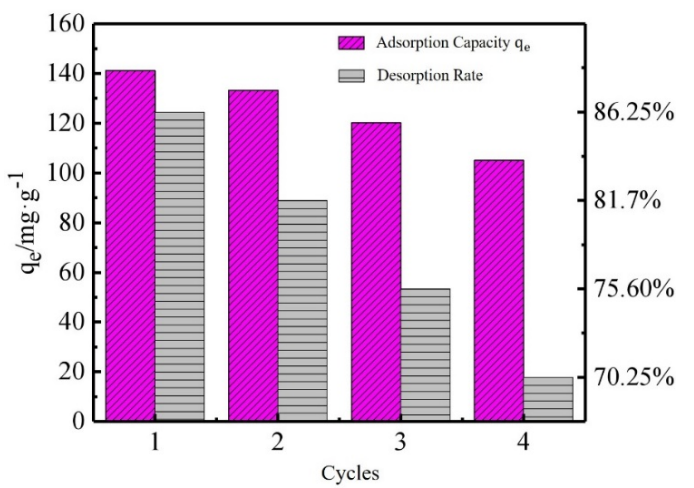

Figure 15. Cycle regeneration experiments. $\left(\mathrm{pH}=8, \mathrm{t}=50 \mathrm{~min}, \mathrm{~T}=45^{\circ} \mathrm{C}, \mathrm{La}(\mathrm{III})\right.$ concentration $=50 \mathrm{mg} \cdot \mathrm{L}^{-1}$, Dosage $=3 \mathrm{~g} \cdot \mathrm{L}^{-1}$ ) 


\section{Conclusions}

In this study, GO was prepared using the improved Hummers' method and was carboxylated and modified into GOH. Thus, DE and chitosan/magnetic chitosan with stable chemical properties, large specific surface areas, wear resistance, and high porosities were loaded by solution blending, and GOH/DCS and GOH/DMCS composites with suitable solid-liquid separation properties were prepared. Through $\mathrm{La}(\mathrm{III})$ adsorption experiments, various effects on adsorption were explored and fitted. The results showed that the adsorption of $\mathrm{La}$ (III) by the GOH/DCS and GOH/DMCS composites reached equilibrium in $50 \mathrm{~min}$, and $\mathrm{pH}$ had the most significant effect on adsorption. When $\mathrm{pH}$ was 8 , the adsorption capacity of La(III) by GOH/DMCS reached $141.19 \mathrm{mg} / \mathrm{g}$. With increasing adsorbent dosage, the adsorption rate gradually increased, while the adsorption capacity gradually decreased. Therefore, the optimum adsorption effect was obtained when the addition amount of adsorbent was $3 \mathrm{~g} \cdot \mathrm{L}^{-1}$, and the reaction temperature and initial solution concentration were $45^{\circ} \mathrm{C}$ and $50 \mathrm{mg} \cdot \mathrm{L}^{-1}$, respectively. The adsorption process of $\mathrm{La}$ (III) by the GOH/DMCS composites followed the pseudo-second-order kinetic model, and adsorption efficiency was not solely controlled by internal diffusion. Thus, the adsorption process was more in line with the Langmuir model, which indicated that the adsorption process followed monolayer adsorption, and the surface contained a limited number of adsorption sites with uniform adsorption energies. Thus, there was no adsorbate migration on the surface. The thermodynamic fitting results showed that adsorption was an endothermic process, and an increase in temperature was beneficial to the reaction. After four adsorption-desorption cycle experiments, the adsorption capacity of the GOH/DMCS composite for $\mathrm{La}(\mathrm{III})$ initially exceeded $74 \%$, and the desorption percentages after several adsorption-desorption cycles decreased only slightly.

Author Contributions: Conceptualization, J.Z. and X.S.; methodology, J.Z.; software, X.S.; validation, X.S., B.S. and S.W.; formal analysis, J.Z.; investigation, B.S.; resources, J.Z.; data curation, B.S.; writingoriginal draft preparation, X.S.; writing—review and editing, J.Z.; visualization, X.S.; supervision, S.W.; project administration, X.S.; funding acquisition, S.W. All authors have read and agreed to the published version of the manuscript. Please turn to the CRediT taxonomy for the term explanation. Authorship must be limited to those who have contributed substantially to the work reported.

Funding: This research was funded by the National Natural Science Foundation of China, grant number 21466019.

Institutional Review Board Statement: Not applicable.

Informed Consent Statement: Not applicable.

Data Availability Statement: The data presented in this study are available on request from the corresponding author. The data are not publicly available due to the author have not graduated.

Conflicts of Interest: The funders had no role in the design of the study; in the collection, analyses, or interpretation of data; in the writing of the manuscript, or in the decision to publish the results.

\section{References}

1. Wu, D.; Zhang, L.; Wang, L.; Zhu, B.; Fan, L. Adsorption of lanthanum by magnetic alginate-chitosan gel beads. J. Chem. Technol. Biotechnol. 2011, 86, 345-352. [CrossRef]

2. Jowitt, S.M.; Werner, T.T.; Weng, Z.; Mudd, G.M. Recycling of the rare earth elements. Curr. Opin. Green Sustain. Chem. 2018, 13, 1-7. [CrossRef]

3. Asadollahzadeh, M.; Torkaman, R.; Torab-Mostaedi, M. Extraction and separation of rare earth elements by adsorption approaches: Current status and future trends. Sep. Purif. Rev. 2021, 50, 417-444. [CrossRef]

4. Iannicelli-Zubiani, E.M.; Gallo Stampino, P.; Cristiani, C.; Dotelli, G. Enhanced lanthanum adsorption by amine modified activated carbon. Chem. Eng. J. 2018, 341, 75-82. [CrossRef]

5. Abdel-Magied, A.F.; Abdelhamid, H.N.; Ashour, R.M.; Zou, X.; Forsberg, K. Hierarchical porous zeolitic imidazolate frameworks nanoparticles for efficient adsorption of rare-earth elements. Microporous Mesoporous Mater. 2019, 278, 175-184. [CrossRef]

6. Kusrini, E.; Usman, A.; Sani, F.A.; Wilson, L.D.; Abdullah, M.A.A. Simultaneous adsorption of lanthanum and yttrium from aqueous solution by durian rind biosorbent. Environ. Monit. Assess. 2019, 191, 488. [CrossRef] 
7. Silva, A.; Martínez-Gallegos, S.; Rosano-Ortega, G.; Schabes-Retchkiman, P.; Vega-Lebrún, C.; Albiter, V. Nanotoxicity for E. Coli and characterization of silver quantum dots produced by biosynthesis with Eichhornia crassipes. J. Nanostructures 2017, 7, 1-12.

8. Kegl, T.; Košak, A.; Lobnik, A.; Novak, Z.; Kralj, A.K.; Ban, I. Adsorption of rare earth metals from wastewater by nanomaterials: A review. J. Hazard. Mater. 2020, 386, 121632. [CrossRef]

9. Chang, S.; Zhang, Q.; Lu, Y.; Wu, S.; Wang, W. High-efficiency and selective adsorption of organic pollutants by magnetic CoFe2O4/graphene oxide adsorbents: Experimental and molecular dynamics simulation study. Sep. Purif. Technol. 2020, 238, 116400. [CrossRef]

10. Zhao, X.; Yang, M. Graphene nanocomposites. Molecules 2019, 24, 2440. [CrossRef]

11. Chen, J.; Yao, B.; Li, C.; Shi, G. An improved Hummers method for eco-friendly synthesis of graphene oxide. Carbon 2013, 64, 225-229. [CrossRef]

12. Zhang, Y.; Wang, L.; Zhang, N.; Zhou, Z. Adsorptive environmental applications of MXene nanomaterials: A review. RSC Adv. 2018, 8, 19895-19905. [CrossRef]

13. Chen, P.; Li, H.; Yi, H.; Jia, F.; Yang, L.; Song, S. Removal of graphene oxide from water by floc-flotation. Sep. Purif. Technol. 2018, 202, 27-33. [CrossRef]

14. Marcano, D.C.; Kosynkin, D.V.; Berlin, J.M.; Sinitskii, A.; Sun, Z.; Slesarev, A.; Alemany, L.B.; Lu, W.; Tour, J.M. Improved synthesis of graphene oxide. ACS Nano 2010, 4, 4806-4814. [CrossRef]

15. Molavi, H.; Zamani, M.; Aghajanzadeh, M.; Kheiri Manjili, H.; Danafar, H.; Shojaei, A. Evaluation of UiO-66 metal organic framework as an effective sorbent for Curcumin's overdose. Appl. Organomet. Chem. 2018, 32, e4221-e4231. [CrossRef]

16. Liu, Y.; Shen, L. From Langmuir Kinetics to First-and Second-Order Rate Equations for Adsorption. Langmuir 2008, 24, 1162511630. [CrossRef] [PubMed]

17. Liu, Y. Is the Free Energy Change of Adsorption Correctly Calculated. J. Chem. Eng. Data 2009, 54, 1981-1985. [CrossRef]

18. Ma, F.; Nian, J.; Bi, C.; Yang, M.; Zhang, C.; Liu, L.; Dong, H.; Zhu, M.; Dong, B. Preparation of carboxylated graphene oxide for enhanced adsorption of U(VI). J. Solid State Chem. 2019, 277, 9-16. [CrossRef]

19. Park, K.-W. Carboxylated graphene oxide-Mn2O3 nanorod composites for their electrochemical characteristics. J. Mater. Chem. A 2014, 2, 4292-4298. [CrossRef]

20. Sun, Z.; Yao, G.; Liu, M.; Zheng, S. In situ synthesis of magnetic $\mathrm{MnFe}_{2} \mathrm{O}_{4}$ / diatomite nanocomposite adsorbent and its efficient removal of cationic dyes. J. Taiwan Inst. Chem. Eng. 2017, 71, 501-509. [CrossRef]

21. Fan, L.; Luo, C.; Lv, Z.; Lu, F.; Qiu, H. Preparation of magnetic modified chitosan and adsorption of Zn(2)(+) from aqueous solutions. Colloids Surf. B Biointerfaces 2011, 88, 574-581. [CrossRef] [PubMed]

22. Khraisheh, M.; Al-Ghouti, M.; Allen, S.; Ahmad, M. The effect of pH, temperature, and molecular size on the removal of dyes from textile effluent using manganese oxides-modified diatomite. Water Environ. Res. 2004, 76, 2655-2663. [CrossRef] [PubMed]

23. Nethravathi, C.; Rajamathi, M. Chemically modified graphene sheets produced by the solvothermal reduction of colloidal dispersions of graphite oxide. Carbon 2008, 46, 1994-1998. [CrossRef]

24. Ghosh, B.; Agrawal, D.C.; Bhatia, S. Synthesis of zeolite A from calcined diatomaceous clay: Optimization studies. Ind. Eng. Chem. Res. 1994, 33, 2107-2110. [CrossRef]

25. Ma, L.L.; Xie, Q.L.; Chen, N.C.; Xu, H.; Zhou, H.M.; Yu, Q.F. In Research on Lead (II) Adsorption Mechanism from Aqueous Solution by Calcium Carbonate Modified Diatomite Absorbent. Mater. Sci. Forum 2018, 921, 21-28. [CrossRef]

26. Bahramian, B.; Ardejani, F.D.; Mirkhani, V.; Badii, K. Diatomite-supported manganese Schiff base: An efficient catalyst for oxidation of hydrocarbons. Appl. Catal. A Gen. 2008, 345, 97-103. [CrossRef]

27. Roy, J.C.; Ferri, A.; Giraud, S.; Jinping, G.; Salaün, F. Chitosan-carboxymethylcellulose-based polyelectrolyte complexation and microcapsule shell formulation. Int. J. Mol. Sci. 2018, 19, 2521. [CrossRef]

28. Li, W.; Xiao, L.; Qin, C. The characterization and thermal investigation of chitosan-Fe3O4 nanoparticles synthesized via a novel one-step modifying process. J. Macromol. Sci. Part A 2010, 48, 57-64. [CrossRef]

29. Bei, Z. Removal Performance and Mechanism of Phenolic Pollutants by Go Based Water Treatment Materials. Ph.D. Thesis, Shandong University, Jinan, China, 2019.

30. Yang, Q.; Wang, X.; Luo, W.; Sun, J.; Xu, Q.; Chen, F.; Zhao, J.; Wang, S.; Yao, F.; Wang, D. Effectiveness and mechanisms of phosphate adsorption on iron-modified biochars derived from waste activated sludge. Bioresour. Technol. 2018, 247, 537-544. [CrossRef]

31. Dai, Y.; Lv, R.; Fan, J.; Zhang, X.; Tao, Q. Adsorption of cesium using supermolecular impregnated XAD-7 composite: Isotherms, kinetics and thermodynamics. J. Radioanal. Nucl. Chem. 2019, 321, 473-480. [CrossRef]

32. Awwad, N.; Gad, H.; Ahmad, M.; Aly, H. Sorption of lanthanum and erbium from aqueous solution by activated carbon prepared from rice husk. Colloids Surf. B Biointerfaces 2010, 81, 593-599. [CrossRef] [PubMed] 